\title{
Unraveling the personalization paradox: The effect of information collection and trust-building strategies on online advertisement effectiveness
}

Citation for published version (APA):

Aguirre Lopez, E., Mahr, F. D., Grewal, D., de Ruyter, J. C., \& Wetzels, M. G. M. (2015). Unraveling the personalization paradox: The effect of information collection and trust-building strategies on online advertisement effectiveness. Journal of Retailing, 91(1), 34-49. https://doi.org/10.1016/j.jretai.2014.09.005

Document status and date:

Published: 01/03/2015

DOI:

10.1016/j.jretai.2014.09.005

Document Version:

Publisher's PDF, also known as Version of record

Document license:

Taverne

Please check the document version of this publication:

- A submitted manuscript is the version of the article upon submission and before peer-review. There can be important differences between the submitted version and the official published version of record.

People interested in the research are advised to contact the author for the final version of the publication, or visit the DOI to the publisher's website.

- The final author version and the galley proof are versions of the publication after peer review.

- The final published version features the final layout of the paper including the volume, issue and page numbers.

Link to publication

\footnotetext{
General rights rights.

- You may freely distribute the URL identifying the publication in the public portal. please follow below link for the End User Agreement:

www.umlib.nl/taverne-license

Take down policy

If you believe that this document breaches copyright please contact us at:

repository@maastrichtuniversity.nl

providing details and we will investigate your claim.
}

Copyright and moral rights for the publications made accessible in the public portal are retained by the authors and/or other copyright owners and it is a condition of accessing publications that users recognise and abide by the legal requirements associated with these

- Users may download and print one copy of any publication from the public portal for the purpose of private study or research.

- You may not further distribute the material or use it for any profit-making activity or commercial gain

If the publication is distributed under the terms of Article $25 \mathrm{fa}$ of the Dutch Copyright Act, indicated by the "Taverne" license above, 


\title{
Unraveling the Personalization Paradox: The Effect of Information Collection and Trust-Building Strategies on Online Advertisement Effectiveness
}

\author{
Elizabeth Aguirre ${ }^{\mathrm{a}, *}$, Dominik Mahr ${ }^{\mathrm{a}}$, Dhruv Grewal ${ }^{\mathrm{b}}$, Ko de Ruyter ${ }^{\mathrm{a}}$, Martin Wetzels ${ }^{\mathrm{a}}$ \\ ${ }^{a}$ Department of Marketing and Supply Chain Management, Maastricht University, Tongersestraat 53, 6211 LM Maastricht, The Netherlands \\ ${ }^{\mathrm{b}}$ Toyota Chair in E-Commerce and Electronic Business, Department of Marketing, Babson College, 213 Malloy Hall, Babson Park, MA 02457, United States
}

\begin{abstract}
Retailers gather data about customers' online behavior to develop personalized service offers. Greater personalization typically increases service relevance and customer adoption, but paradoxically, it also may increase customers' sense of vulnerability and lower adoption rates. To demonstrate this contradiction, an exploratory field study on Facebook and secondary data about a personalized advertising campaign indicate sharp drops in click-through rates when customers realize their personal information has been collected without their consent. To investigate the personalization paradox, this study uses three experiments that confirm a firm's strategy for collecting information from social media websites is a crucial determinant of how customers react to online personalized advertising. When firms engage in overt information collection, participants exhibit greater clickthrough intentions in response to more personalized advertisements, in contrast with their reactions when firms collect information covertly. This effect reflects the feelings of vulnerability that consumers experience when firms undertake covert information collection strategies. Trust-building marketing strategies that transfer trust from another website or signal trust with informational cues can offset this negative effect. These studies help unravel the personalization paradox by explicating the role of information collection and its impact on vulnerability and click-through rates. (C) 2014 New York University. Published by Elsevier Inc. All rights reserved.
\end{abstract}

Keywords: Personalization paradox; Information collection; Trust-building strategies; Vulnerability; Psychological ownership

Retailers use sophisticated, personalized marketing strategies that exploit consumer data to influence purchase decisions (Hawkings 2012), so much so that these data have become the "life-blood of retail" (National Retail Federation n.d., p. 20). Many online retailers partner with publishers such as Google and Yahoo that collect consumer data, then use the collected information to present personalized advertisements (Angwin 2012). In addition, with the spread of social networking sites, retailers-which represent the largest sector of Internet advertising spending, accounting for $22 \%$ in 2011 (Interactive Advertising Bureau 2012)-have entered into these media spheres to present consumers with more targeted advertising. Facebook thus became the most popular ad publisher in

\footnotetext{
* Corresponding author. Tel.: +31 4338 83716; fax: +31 433884918 .

E-mail addresses: e.aguirrelopez@maastrichtuniversity.nl (E. Aguirre), d.mahr@maastrichtuniversity.nl (D. Mahr),dgrewal@babson.edu (D. Grewal),k.deruyter@maastrichtuniversity.nl (K. de Ruyter), m.wetzels@maastrichtuniversity.nl (M. Wetzels).
}

2011, with a 31.2\% market share (comScore 2011), but also has come under close scrutiny of its advertising practices and covert data collection methods (Singer 2010). These trends suggest the need for retailers to find more sustainable methods of data collection and use (McCann Worldwide 2011).

Advocates of covert data collection techniques contend that the consumer benefits from them, because the data collection does not disrupt their online surfing experience (Milne, Bahl, and Rohm 2008), whereas granting consent to each data collection encounter would force users to take 2.5 times longer to complete online tasks (Interactive Advertising Bureaux Europe 2011) and disrupt the flow of their shopping (National Retail Federation n.d.). Yet consumers may experience discomfort when they receive personalized advertisements (Tucker 2012), because it prompts them to realize their information has been collected without their consent. For example, when the U.S. retailer Urban Outfitters launched a website that personalized each customer's experience by gender, customers instantly recognized the personalization and confronted the clear knowledge that the 
retailer had collected their information without their awareness. They reacted by accusing Urban Outfitters of being "too close for comfort" and making illegitimate uses of their data, which quickly led Urban Outfitters to abandon the personalization strategy (Singer 2012). Thus, despite evidence that response rates improve with greater personalization, such efforts also could increase consumer discomfort, leading to lower response rates. This phenomenon gives rise to what we refer to as the personalization paradox: Personalization can be both an effective and an ineffective marketing strategy, depending on the context. The effects of various data collection methods on this paradox remain unclear, though retailers using online advertising could benefit from recommendations about which tools or marketing communication to use to avoid or minimize the negative effects of personalization.

Current research offers little guidance; it mostly emphasizes consumers' reactions to the delivery of personalized services (Sundar and Marathe 2010; Tam and Ho 2006), without accounting for the information collection process needed to personalize services or consumers' reactions. Literature on covert marketing practices provides some insights though. For example, Miyazaki (2008) studies disclosures of the use of cookies, a common covert information collection technique, and finds that when consumers realize a cookie is going to be installed (e.g., after notification on web browsers) but receive no prior disclosure in privacy statements, they exhibit lower behavioral intentions toward the website. Although personalization can signal greater relevance and increase customer adoption (Tam and Ho 2006), no research indicates whether it triggers negative reactions similar to those prompted by an explicit cookie notification (Miyazaki 2008).

Furthermore, research that addresses the mechanism underlying negative reactions to data uses tends to rely on cognitive reasoning, such that customers weigh the pros and cons of allowing firms to use their data (Awad and Krishnan 2006). Yet in many cases, consumers form attitudes quickly, instinctively, and without in-depth thinking, in reaction to a stimulus (Shiv and Fedorikhin 1999). Such affective responses strongly influence retail shopping experiences (Arnold and Reynolds 2009) and consumer judgments (Avnet, Pham, and Stephen 2012). Milne, Bahl, and Rohm (2008) suggest that consumers may experience an affective sense of vulnerability in response to covert information collection, but empirical tests of this proposition or its implications for consumer behavior are lacking. In addition, customers likely accept feelings of vulnerability in environments marked by trust (Urban, Amyx, and Lorenzon 2009), and various retailer-driven marketing strategies seemingly might increase customer trust (Bart et al. 2005; Kim and Kim 2011; Pan and Zinkhan 2006). Such trust-building strategies in turn might offset the negative reactions brought about by feelings of vulnerability.

This article seeks to make three main contributions. First, using evidence from exploratory field studies on Facebook and secondary data, we corroborate the existence of the personalization paradox and probe the interdependencies among the collection and use of data for personalization and their impact on consumer behavior in social media settings. This effort represents a response to calls for more empirical generalizations related to personalization strategies in retailing (Grewal et al. 2011). With new insights into the personalization paradox, we find that employing covert data collection undermines the beneficial impact of increased relevance on advertising effectiveness. Second, we conceptualize consumers' perceived vulnerability as a negative influence on the experience of personalization in social media-mediated environments. Drawing on psychological ownership theory, we propose that vulnerability occurs when personalization provokes discomfort, because the consumer comes to a sudden realization of the covert data collection. This conceptualization offers an affective alternative to the common cognitive rationale for low click-through rates on online advertisements, namely, as due to privacy concerns. In turn, we operationalize consumer vulnerability with a newly developed, robust, five-item measure and validate its impact on advertising effectiveness. Third, we test the impact of two trust-building strategies-transferring trust from the media context or signaling trust with cues-that may offset the experience of vulnerability. If the personalized advertisement appears on a trustworthy website, its credibility can mitigate the negative effect of covert data collection. Similarly, information icons that systematically inform customers about how their information is being collected and used provide trustbuilding cues that can reduce the negative impacts of covert data collection.

\section{Conceptual Background}

\section{Personalization}

Personalization refers to a customer-oriented marketing strategy that aims to deliver the right content to the right person at the right time, to maximize immediate and future business opportunities (Tam and Ho 2006). The strength of this strategy is that it requires a minimum amount of effort by the customer, who relies mostly on the marketer to identify and meet his or her needs (Montgomery and Smith 2009). This central aspect of personalization provides a stark contrast with customization, which occurs when the consumer specifies the elements of his or her preferred marketing mix (Arora et al. 2008).

Firms routinely practice personalization, both offline and online. In face-to-face service encounters, firms encourage employees to adjust their behaviors toward each customer, such as referring to a customer by name or modifying the service offering to accommodate customers' needs (Shen and Ball 2009). The applicability of personalization expands significantly in online environments too. Search engines, such as Google and Yahoo, can refine each user's search results by incorporating prior search information; online retailers, such as Amazon.com and Barnes \& Noble, provide personalized recommendations based on collaborative filtering, that is, on a user's similarity to other users and their preferences (Montgomery and Smith 2009). Online advertisers also issue behaviorally targeted advertisements, reflecting a user's online behavior (Goldfarb and Tucker 2011). 
This ability to incorporate users' past behaviors also enables online firms to personalize services more accurately, with advantages for both the firms and their customers. Briefly, customers enjoy improved products and services, a better preference match (Vesanen 2007), reduced cognitive overload, and convenience (Ansari and Mela 2003). Firms can better service their customers, which increases customer satisfaction (Rust and Chung 2006) and loyalty (Ansari and Mela 2003), and better manage customers' perceptions of their responsiveness (Song and Zinkhan 2008). Moreover, they might gain competitive advantages (Murthi and Sarkar 2003), charge higher prices (Vesanen 2007), and improve their profitability (Rossi, McCulloch, and Allenby 1996; Zhang and Wedel 2009). In an online advertising context, firms also benefit from greater recall, higher content evaluations, and more purchases (Tam and Ho 2006), such that personalized advertisements appear twice as effective as similar, impersonal versions (Tucker 2014).

Murthi and Sarkar (2003) specify three personalization stages: learning, matching, and evaluation. In the learning stage, firms collect and analyze customer data to understand their needs and preferences. The matching stage involves applying this information to personalize a customer's experience; for our study context, it implies presenting a customer with a personalized advertisement. Finally, evaluating the effectiveness of the personalization strategy demands consideration of the learning and matching stages. In online settings, this last stage translates into evaluating the effectiveness of the personalized strategy with measurable instruments, such as click-through rates.

Because personalization inherently involves adapting to customer needs, it is essential for firms to learn about customers. The strategies that firms employ to collect such data differ in the degrees to which consumers are aware of how and when their information gets collected. We thus delineate two data collection strategies: overt and covert (Murthi and Sarkar 2003; Sundar and Marathe 2010).

\section{Information Collection}

When firms engage in overt information collection strategies, consumers know their data are being collected (Sundar and Marathe 2010), because the firm has made a conscious effort to inform them. The underlying assumption is that continued use of the services, after this information provision, creates an ad hoc consent to the data collection. For example, The Economist's website clearly informs readers about its use of cookies; an information box appears in the header of each page (www.economist.com). Privacy advocates stress the importance of information transparency and consent, but practitioners tend to argue that excessive consent requests could be detrimental to consumers' surfing experiences (Interactive Advertising Bureaux Europe 2011). For example, the "irritating" nature of the Dutch "cookie law" led to suggestions to rescind the requirement that websites obtain permission from visitors to use cookies every time they visit a site (DutchNews.nl 2013).

Covert information collection strategies instead occur when firms collect data without consumers' awareness, often by unobtrusively gathering information while the consumer browses the
Internet (Milne, Bahl, and Rohm 2008; Montgomery and Smith 2009). The unobtrusiveness of this form of data collection helps the firm gain unbiased data, and thus a richer customer understanding that it can use to tailor its services (Verhoef et al. 2010). It also benefits consumers, by not interfering with their surfing experience. Because consumers are not informed of each discreet instance of information collection, the ad hoc consent assumed in overt information collection settings cannot apply (John, Acquisti, and Loewenstein 2011). Consumers' demands for more openness thus pose a challenge to firms that prefer to continue to practice covert strategies (Turow et al. 2009).

\section{Link Between the Personalization Paradox and Information Collection}

Personalization requires the collection and use of consumer data to make inferences about their preferences (Montgomery and Smith 2009). Although Internet users generally realize that firms, such as social networking sites, collect their information, they often become aware of these discreet instances only if the firm overtly informs them that it is doing so. When firms do not inform their customers about their data collection efforts, an advertisement that contains distinct, personal information may cue customers that their information has been collected, without their consent. Milne, Bahl, and Rohm (2008) suggest that exposure to such cues results in negative customer reactions and thus harms the firm's reputation and future business. For example, customers might perceive that the firm is acting in its own self-interest, which would lower their perceptions of its benevolence and value offering (Shen and Ball 2009). We expect the effect of personalization on consumers' click-through intentions to be moderated by their awareness of the collection of personal data. Moreover, the positive benefits of personalization should accrue when the firm engages in overt, as opposed to covert, information collection.

H1. When firms engage in overt information collection, more personalized (cf. less personalized) advertisements enhance click-through intentions, but not when firms engage in covert data collection.

\section{Cognitive Theories}

Two literature streams related to privacy and reactance seek to explain the negative consequences of personalization using cognitive approaches. First, investigations of privacy feature various considerations, including the importance of regulatory and parental interventions for limiting underage disclosures (Lwin, Stanaland, and Miyazaki 2008) and the effects of privacy on retailer quality perceptions (Wolfinbarger and Gilly 2003). The application of privacy theories to explicate personalization outcomes often emphasize the trade-off between the benefits of personalization and the costs of privacy. In this cost-benefit analysis, consumers act as rational economic agents, who consider both the risks and benefits prior to disclosing their information and form perceptions of the personalized service (Awad and Krishnan 2006; Chellappa and Shivendu 2010; John, Acquisti, 
and Loewenstein 2011; Pavlou 2011). This rational assessment and deliberate decision process suggest that sharing private information is a cognitive, rather than affective, concept.

Second, personalized messages can lead users to perceive threats to their freedom, in terms of their ability to avoid being closely observed by a firm (Brehm 1966). In response to this threat, customers may exhibit reactance and attempt to reattain their restricted freedom (Fitzsimons and Lehmann 2004). In light of this, White et al. (2008) find that higher levels of personalization are less effective if customers receive no justification for why their information has been used. Building on this finding, Tucker (2014) shows that introducing privacy controls increases the effectiveness of personalized advertisements by reducing reactance. Reactance "describes a strategy that consumers use to avoid complying with a persuasion attempt but does not directly characterize the cause of discomfort associated with a privacy invasion" (Tucker 2012, p. 2). Therefore, we turn to psychological ownership theory and describe an affective process that might explain the discomfort and ultimately the paradox.

\section{Psychological Ownership and Vulnerability as an Affective Alternative}

Psychological ownership is a state in which a person has a sense of ownership over external objects (Pierce, Kostova, and Dirks 2001), because of his or her strong cognitive and affective attachment to them (Avey et al. 2009). These owners then perceive a right to gain information about the objects and a voice in decisions that affect them (Pierce, Kostova, and Dirks 2001). Violations of these expectations produce strong negative emotions; removal of the possessed objects causes people to feel acute loss, such that they may be "personally annihilated" (James 1981, p. 280) or sense a loss of self (Belk 1988).

Vulnerability arises when consumers lack of a sense of control over the situation and experience a state of powerlessness, brought about by marketplace imbalances (Baker, Gentry, and Rittenburg 2005). Consumers may feel vulnerable if firms engage in certain actions that make them feel exploited (Andreasen, Cooper-Martin, and Smith 1994). Such an experience is marked by strong emotional intensity, caused by the acute threat to their self-concept, such that the individual even could feel as if her or his security and well-being were at risk (Baker, Gentry, and Rittenburg 2005; Pierce, Kostova, and Dirks 2001). In contrast with cognitive theory-based predictions, feelings of vulnerability emerge subconsciously and may be hard to express, despite their strong impact. Research also indicates that this feeling of vulnerability may shape privacy concerns, which suggests the potential relationship between these constructs (Bandyopadhyay 2009; Dinev and Hart 2004).

When customers recognize covert information collection, through exposure to highly personalized advertisements, they likely perceive a loss of control and experience feelings of vulnerability. Vulnerability is highly undesirable, so consumers avoid objects associated with it. In contrast, when customers receive details about information collection strategies prior to their exposure to highly personalized advertisements, they are less likely to perceive a loss or experience feelings of vulnerability, because they have granted implied consent, through their awareness. We thus posit that the influence of personalized advertisements on consumers' click-through intentions depends on their awareness that personalization is taking place. When consumers become aware of covert information collection only through their exposure to a highly personalized advertisement, they sense greater vulnerability and express lower click-through intentions in response to highly personalized advertisements; when they are exposed to overt information collection, they do not experience feelings of vulnerability and indicate greater click-through intentions.

H2. When firms engage in covert information collection, more personalized (cf. less personalized) advertisements increase feelings of vulnerability, but not when firms engage in overt data collection.

\section{Trust-Building Strategies}

Trust, as "a psychological state comprising the intention to accept vulnerability based on positive expectations of the intentions or behaviors of another" (Rousseau et al. 1998, p. 395 ), is especially important online, due to the vast information asymmetries and customer uncertainty inherent to the Internet (Stewart 2003). For example, consumers cannot ascertain how retailers use information about their shopping behaviors on websites. Without any means to determine whether a firm is acting in their own best interests, consumers may remain unwilling to grant firms more control over the interaction (Bart et al. 2005; Urban, Amyx, and Lorenzon 2009). Online advertisers therefore pursue various strategies, such as relying on a particular website's credibility or using signaling cues, to build more trust in their advertisements, which then should improve click-through rates.

Online advertisers can take advantage of a trustworthy website by capitalizing on the potential spillover of trust from the website to an advertisement. Consumers tend to believe that advertisements follow the norms of the websites on which they appear (Stewart 2003), so if a web surfer trusts a particular website, he or she likely assumes that the assurances and safeguards related to the site also pertain to the advertisements on the site. In turn, they are more likely to accept a sense of vulnerability to trustworthy websites (Pavlou, Liang, and Xue 2007). If such websites feature highly personalized advertisements, we expect that consumers accept this form of vulnerability, despite the covert data collection, and exhibit higher click-through intentions than they would in response to an advertisement on an untrustworthy website. That is, we predict that vulnerability decreases click-through intentions only if consumers are exposed to highly personalized advertisements on an untrustworthy website.

H3. When firms engage in covert data collection, more personalized advertisements decrease click-through intentions if the advertisement appears on a less trustworthy (cf. more trustworthy) website, due to their increased feelings of vulnerability. 
Alternatively, firms might seek to increase consumer trust through cues that signal their benevolence and reliability (Kim and Kim 2011). The Internet Advertising Bureau UK (2011) urges firms to incorporate icons to inform users about data collection and usage practices; such icons could increase trust perceptions (Pan and Zinkhan 2006), benevolence and integrity beliefs (Schlosser, White, and Lloyd 2006), and behavioral intentions (Wang, Beatty, and Foxx 2004). When advertisers incorporate icons directly into an advertisement, consumers may experience more trust and become more willing to accept vulnerability, such that they will click on a highly personalized advertisement that contains a trust-building cue, despite their recognition of covert data collection attempts by the firm.

H4. When highly personalized advertisements contain trustbuilding cues, click-through intentions do not differ whether the information has been collected overtly or covertly.

To establish empirical evidence of the predicted personalization paradox, we undertook an exploratory field study on Facebook (Prestudy 1) to demonstrate the differential effects of personalization. We also gathered secondary data about a personalized advertising campaign (Prestudy 2) that attributed the decrease in effectiveness to covert information collection. As in-depth analyses, we conducted three experimental studies: Study 1 examines the impact of the interaction between information collection and personalized strategies on click-through intentions, revealing a central role of vulnerability in reducing the effectiveness of personalization. In Study 2, we investigate whether website credibility can offset the negative effects of vulnerability, and in Study 3, we consider the effectiveness of the industry-advocated solution of incorporating information icons into the advertisement.

\section{Prestudy 1}

A field experiment on Facebook provides some insights into the personalization paradox. Retailers often sell both services and products, so for this field experiment on Facebook, we selected a brand in each category: a well-known financial services brand and a familiar dog food brand sold in the Netherlands. The experiment featured three advertisements. The first contained no personalization; the second was moderately personalized, targeting people who indicated that they liked financial services or dogs; and the third was highly personalized, with content that reflected both liking of financial services or dogs and the participants' demographic characteristics (i.e., age, gender, location). The advertisements ran for five days on Facebook, during which we collected the aggregated click-through rates (CTR).

\section{Results}

The results for the financial services brand showed significant increases in CTR when participants received more relevant advertisements, reflecting their indicated preferences $\left(\mathrm{CTR}_{\text {no personalization }}=.017 \%\right.$, $\left.\mathrm{CTR}_{\text {moderate personalization }}=.077 \% ; \quad z=-4.61, \quad p \leq .001\right)$.
a.Financial Services

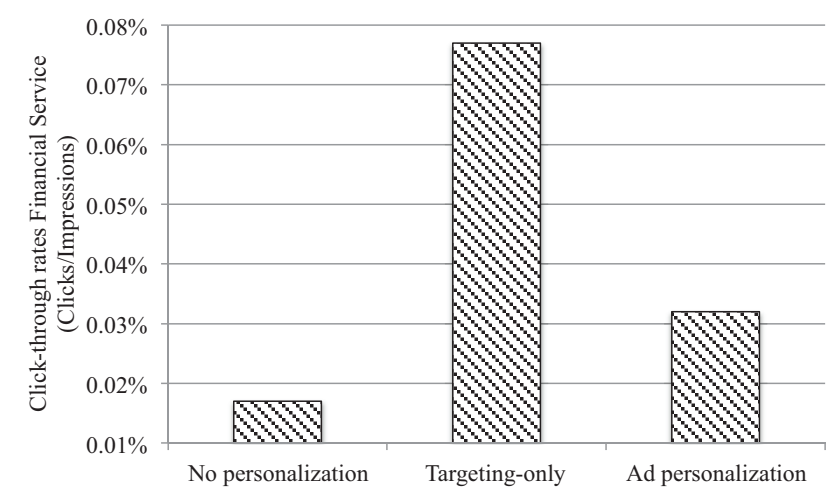

b. Dog Food

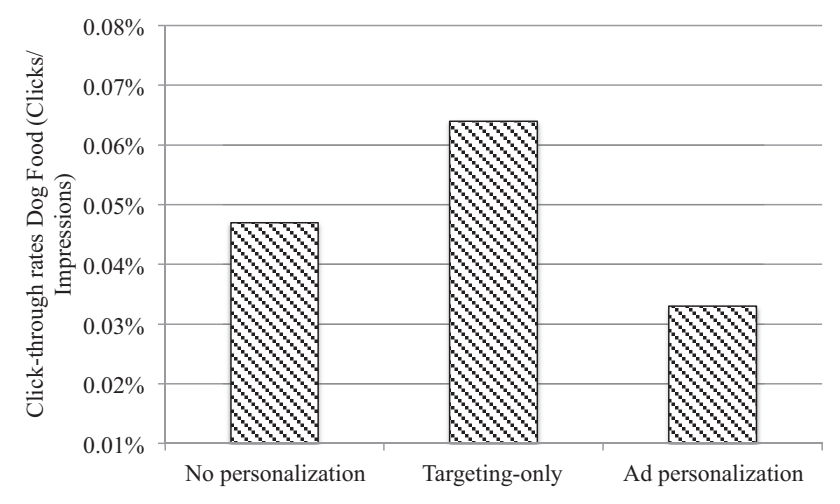

Fig. 1. Click-through rates.

However, when participants received a targeted advertisement with specific personal information, the CTR significantly decreased $\left(\mathrm{CTR}_{\text {moderate personalization }}=.077 \%\right.$, $\mathrm{CTR}_{\text {high personalization }}=.032 \% ; \quad z=3.15, \quad p=.002 ; \quad$ see Fig. 1, Panel a). Similar findings emerged for the dog food brand, with significant CTR increases from no to moderate personalization $\left(\mathrm{CTR}_{\text {no personalization }}=.047 \%\right.$, $\mathrm{CTR}_{\text {moderate personalization }}=.064 \% ; \quad z=-1.38, \quad p=.084$, one-tailed) but significant decreases from moderate to high personalization $\left(\mathrm{CTR}_{\text {moderate personalization }}=.064 \%\right.$, $\mathrm{CTR}_{\text {high personalization }}=033 \% ; z=2.60, p=.009$, two-tailed; see Fig. 1, Panel b).

\section{Discussion}

These findings offer evidence of the personalization paradox. Observing consumers' behaviors in the real world, we find that they react differently to advertisements with varied personalization levels. Some personalized advertisements are effective, but others fail to induce desired behaviors, such as clicking on the advertisement. The realization that personalization's effects are not entirely straightforward highlights the need to explicate its functioning in different contexts, to gain insights into best management practices. Information collection strategies largely determine the personalization process, so we investigate how such strategies affect customers' reactions to personalized advertisements. 


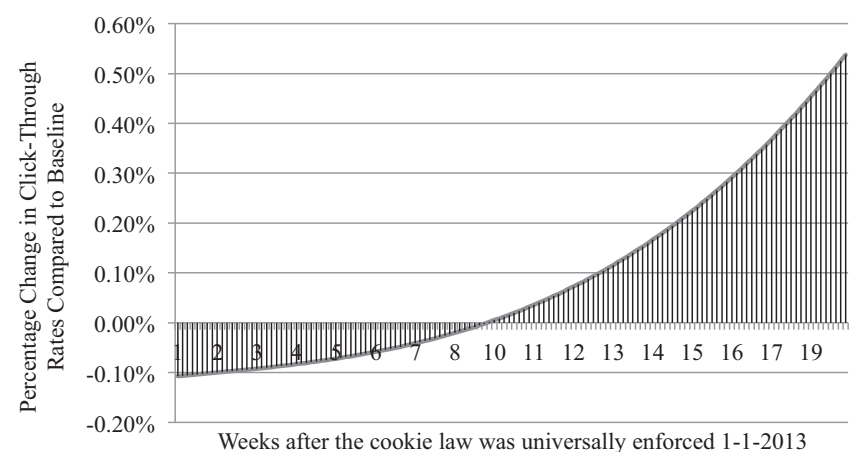

Fig. 2. Percentage change in click-through rates due to cookie law in the Netherlands.

\section{Prestudy 2}

In early January 2013, the Dutch government began enforcing its "cookie law," which obliged all websites to inform visitors of their cookie usage policies and receive express permission (DutchNews.nl 2013). Online visitors suddenly confronted evidence of the extent to which their information was being collected, similar to the effects of receiving a highly personalized advertisement. Therefore, reactions to the enforcement of the cookie law might mimic the reactions to the recognition of covert information collection. Accordingly, we acquired the CTR for a personalized advertising campaign run by a Dutch financial services provider over the course of a year. Midway through the campaign, the government began enforcing the cookie law, which created a natural comparison of CTR before and after enforcement.

Specifically, we modeled CTR as exponential functions of the explanatory variables:

$\mathrm{CTR}_{t}=\exp \left[\alpha+f(t)+I_{t} \times k(t)+\varepsilon_{t}\right]$,

where $\mathrm{CTR}_{t}$ indicates the click-through rate (clicks/impressions) on day $t(i=1,2, \ldots, 381) ; \alpha$ is the intercept to be estimated; $f(t)$ refers to the function that captures the baseline fluctuations, whose parameters must be estimated; $I_{t}$ is an indicator equal to 1 if day $t$ occurred after the cookie law was enacted, and 0 otherwise, for which parameters need to be estimated; $k(t)$ captures the incremental change in CTR due to the enactment of the cookie law, for which the parameters must be estimated; and $\varepsilon_{t}$ is a normally distributed error term.

The results of the analysis (see Fig. 2) show that CTR significantly drops from the baseline immediately after the introduction of the cookie law $(-11 \%)$; after nine weeks, the CTR rebounds, exceeds the initial baseline, and then continues to increase thereafter. That is, right after the initial enforcement of the cookie law, customers reacted negatively to indicators that sparked their realization that their information was being collected without their consent. However, as time passed and people grew accustomed to the data collection, they apparently began to appreciate the transparency provided by the cookie information and increased their CTR. To specify the mechanism that drives this phenomenon, we embarked on a series of studies to test the effect when customers consider personalized advertisements, which may create responses similar to those prompted by the Dutch cookie law.

\section{Study 1}

With Study 1, we seek to untangle the personalization paradox by testing the predicted interaction effect (personalization $\times$ information collection) by which more personalized advertisements increase click-through intentions when firms openly inform customers of the information collection. We also test whether more personalized advertisements increase perceived vulnerability if firms fail to inform customers of this collection. For these tests, we selected Facebook as the setting, considering the importance of promotions through social media (Shankar et al. 2011) and Facebook's vast popularity (comScore 2011). In a pretest, we identified financial services as an appropriate category to advertise online; respondents perceived their financial information as very sensitive.

\section{Method}

Design and procedure. One hundred thirty-seven participants from an online panel who were familiar with Facebook completed the survey. Seventeen participants did not meet the quality requirements set in advance (i.e., too little or excessive time examining the advertisement manipulation, ${ }^{1}$ too little or too much time completing the survey, such that the respondent appeared to have started and then left off to do something else), so we excluded them from the analysis. (These standards remained constant across all three of our main studies.) Thus, 120 respondents participated in a 2 (less vs. more personalized advertisement $) \times 2$ (overt vs. covert information collection) between-subjects design.

The participants were informed that they would complete a comprehension task to test their ability to recall and understand text presented in two newspaper articles. The first article contained the information collection manipulation; the second was a filler article. After reading each article, the respondents answered three filler questions that tested their comprehension. The varying last paragraph in the first article served to manipulate the study conditions (see Appendix 1): Respondents in the overt condition read that Facebook users were aware that Facebook used their data to create personalized advertisements; respondents in the covert condition read that Facebook users were unaware of this usage. Next, we told the respondents that they would be participating in a different study, in which they would imagine that they needed a car loan to purchase a new car and therefore sent a message to a friend through Facebook to ask for information about car loans (see Appendix 2). The scenario explained that after sending the message, they would be redirected to Facebook's homepage. This page contained an

\footnotetext{
1 A prestudy with 108 students in a laboratory setting established the minimum (11.20 s) and maximum (29.05 s) time needed to examine the manipulation containing the advertisement.
} 


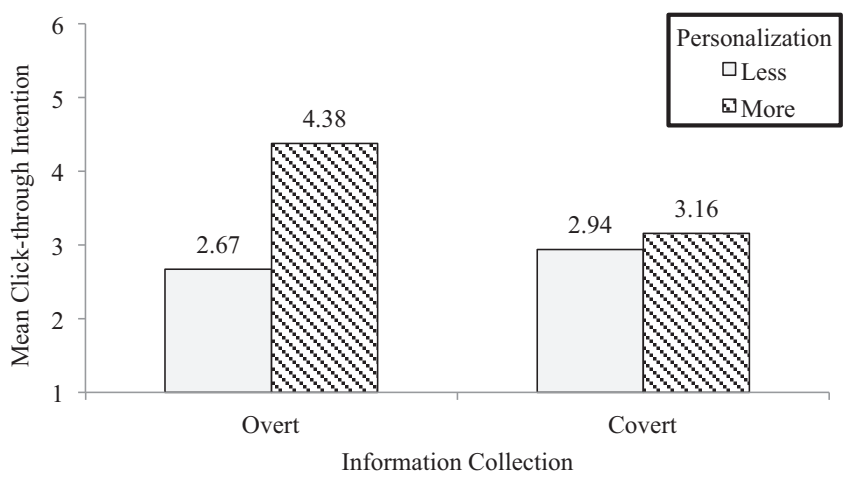

Fig. 3. Study 1: Effects of information collection with less and more personalization on click-through intentions.

advertisement either slightly (less personalized) or closely (more personalized) related to the scenario (see Appendix 3).

Measures. After reviewing the advertisement, participants responded to a click-through intention measure and a five-item perceived vulnerability measure, both on seven-point Likert scales ("strongly agree" to "strongly disagree"). A single item assessed click-through intentions: "I would like to click on the advertisement to get further information." Perceived vulnerability was measured using a multi-item, self-reported scale, which we developed for this study (see Appendix 4) using the suggested procedures for multi-item scale development (Netemeyer, Bearden, and Sharma 2003). Respondents indicated the extent to which the advertisement made them feel "exposed," "unprotected," "susceptible," "unsafe," and "vulnerable" $(\alpha=.88)$.

\section{Results}

Manipulation check. Participants completed four items (Dijkstra 2005) to indicate the level of personalization in the advertisement ("This advertisement is directed to me personally"; "I recognize my personal situation in this advertisement"; "This advertisement takes into account the problem I faced"; "This advertisement takes into account my personal situation"; $\alpha=.93$ ). They identified the more personalized condition as significantly more personalized than the less personalized version $\left(M_{\text {less }}=4.32, M_{\text {more }}=5.00 ; t(118)=-2.53\right.$, $p=.013)$. Respondents in the overt condition also agreed more strongly with the statements, "Facebook users grant Facebook access to their personal information" $\left(M_{\text {overt }}=5.84\right.$, $\left.M_{\text {covert }}=4.69 ; t(118)=-4.01, p<.001\right)$ and "Facebook users are aware that information about them is collected" $\left(M_{\text {overt }}=5.34\right.$, $\left.M_{\text {covert }}=3.34 ; t(118)=-6.85, p<.001\right)$.

Click-through intentions. We validated our prediction using a between-subjects analysis of variance (ANOVA) with click-through intentions as the dependent variable and personalization, information collection, and their interactions as the independent variables. The main effect of personalization was significant $(F(1,116)=7.79, p=.006)$, but that of information collection was not $(F(1,116)=1.87, p=.174)$. As Fig. 3 shows, the personalization $\times$ information collection interaction effect on click-through intentions was significant

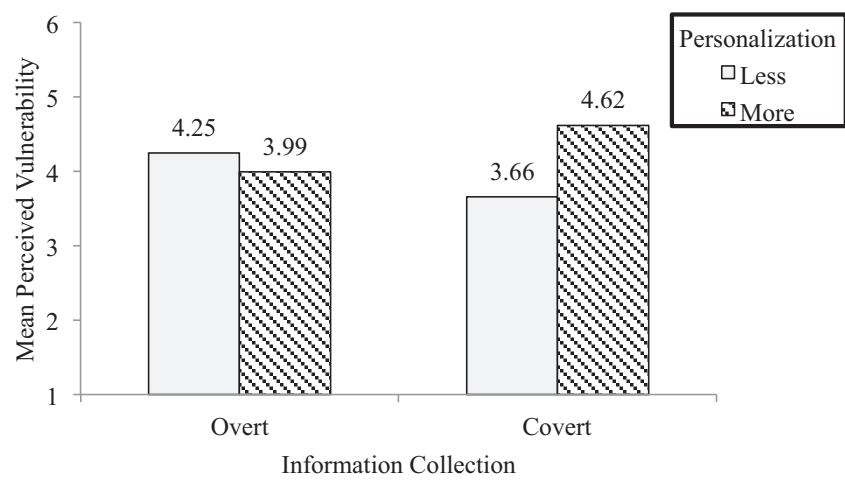

Fig. 4. Study 1: Effects of information collection with less and more personalization on perceived vulnerability.

$(F(1,116)=4.64, p=.033)$, in support of H1. Follow-up contrasts revealed no difference in click-through intentions when respondents in the covert manipulation received a more rather than less personalized advertisement $\left(M_{\text {less }}=2.94, M_{\text {more }}=3.16\right.$; $F(1,116)=.22, p=.641)$. However, when respondents in the overt manipulation viewed a more personalized advertisement, they reported greater click-through intentions $\left(M_{\text {less }}=2.67\right.$, $\left.M_{\text {more }}=4.38 ; F(1,116)=11.44, p=.001\right)$. Thus, the more personalized advertisement in the overt condition increased click-through intentions, but in the covert condition, we found no changes.

Perceived vulnerability. To examine respondents' perceived vulnerability, we used another between-subjects ANOVA, with perceived vulnerability as the dependent variable and personalization, information collection, and their interactions as the independent variables. Neither main effect, of personalization $(F(1,116)=1.92, p=.168)$ or information collection $(F(1,116)=.01, p=.946)$, was significant. However, Fig. 4 reveals a significant personalization $\times$ information collection interaction effect on perceived vulnerability $(F(1,116)=5.88$, $p=.017$ ), in support of H2. Respondents in the covert condition perceived more vulnerability in the more personalized condition $\left(M_{\text {less }}=3.66, M_{\text {more }}=4.62 ; F(1,116)=7.80, p=.006\right)$, whereas respondents in the overt condition perceived no difference in vulnerability $\left(M_{\text {less }}=4.25, M_{\text {more }}=3.99 ; F(1,116)=.50, p=.479\right) .^{2}$

Mediation. To determine if perceived vulnerability mediated the effect of the personalization $\times$ information collection interaction on click-through intentions (Muller, Judd, and Yzerbyt 2005; Preacher, Rucker, and Hayes 2007), we ran three regression models. First, the regression with click-through intentions as the dependent variable and personalization, information collection, and their interaction as the independent variables demonstrated a significant personalization $\times$ information collection interaction effect on click-through intentions $(\beta=.37$, $t(116)=2.15, p=.033)$. Second, a regression with perceived vulnerability as the dependent variable and the same independent variables indicated a significant personalization $\times$ information collection interaction effect, this time on perceived vulnerability

\footnotetext{
${ }^{2}$ A two-cell post-control condition resulted in no significant differences for the covert conditions pertaining to either click-through intentions or vulnerability.
} 


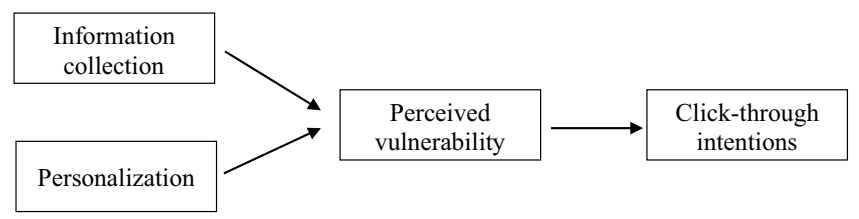

Fig. 5. Study 1: Mediated moderation model.

$(\beta=-.31, t(116)=-2.42, p=.017)$. Third, adding perceived vulnerability and the interaction between perceived vulnerability and information collection to the first model revealed a significant effect of perceived vulnerability on click-through intentions $(\beta=-.36, t(114)=-2.82, p=.006)$. This regression also showed that the interaction between personalization and information collection was no longer significant $(\beta=.25$, $t(114)=1.45, p=.150)$. The magnitude of the personalization $\times$ information collection interaction decreased from $\beta=.37$ $(t(116)=2.15, p=.033)$ to $\beta=.25 \quad(t(114)=1.45, p=.150)$. The conditional indirect effects (Preacher, Rucker, and Hayes 2007) confirmed the mediating role of perceived vulnerability for the covert condition $(z=-2.00, p=.045)$ but not for the overt condition $(z=.66, p=.510)$. Thus, vulnerability mediated the effects of personalization and information collection on click-through intentions, and participants in the covert condition expressed lower click-through intentions because they felt vulnerable, ${ }^{3}$ as we summarize in Fig. 5.

\section{Discussion}

These results provide evidence of the personalization paradox. In some conditions, personalization leads to greater click-through intentions; specifically, and consistent with our prediction, more personalization increases click-through intentions when firms overtly collect consumer data to provide personalized services. When firms covertly collect data though, consumers feel more vulnerable when they realize their information has been collected without their permission, which decreases their click-through intentions. Because decreasing this sense of vulnerability can increase the effectiveness of personalized advertising, we next consider how retailers might establish trust as a means to counter the negative effects.

\section{Study 2}

The credibility of a website that contains an advertisement strongly influences that advertisement's effectiveness, by determining consumers' perceptions of its value (Aaker and Brown

\footnotetext{
${ }^{3}$ We conducted an additional study $(n=39)$ to examine the effects of a cognitive response measure (i.e., privacy) along with the affective response (i.e., vulnerability). All participants saw the covert manipulation but were randomly assigned to view either the less or more personalized advertisement. In addition, the order of the vulnerability and privacy measures were randomized, to avoid order effects. The privacy measure came from Tolchinski et al. (1981; $\alpha=$.816). The results were substantially the same, with no significant differences between the less and more personalized advertisements for click-through intentions ( $p=.507)$, as well as no differences for privacy $(p=.298)$, but a significant difference for vulnerability ( $p=.043$, one-tailed).
}

1972), their attitudes toward the advertisement, and their behavioral intentions (click-through, purchase) (Choi and Rifon 2002; Shamdasani, Stanaland, and Tan 2001). Trust is particularly vital for managing situations that involve vulnerability and potential transactions (Gupta, Yadav, and Varadarajan 2009). Because trust transfers from a website to the advertisements it hosts (Stewart 2003), the setting should influence the effectiveness of a personalized advertisement; McCann Worldwide (2011) cites Facebook as among the least trusted online brands though. In Study 2, to test the prediction that personalized advertisements decrease click-through intentions when firms engage in covert data collection if the advertisement appears on a less trustworthy website, we use the popular CNN news website as a more trustworthy site and Facebook as the less trustworthy version. The mediation effects of vulnerability should emerge among participants who view an advertisement on Facebook but not for those who view the same advertisement on CNN.

\section{Method}

Design and procedure. Two hundred fifty-one participants from an online panel who were familiar with Facebook participated in a 2 (less vs. more personalized advertisement) $\times 2$ (overt vs. covert information collection) $\times 2$ (Facebook vs. CNN) between-subjects design. We used a screening procedure to test their attention and motivation: Participants answered an open-ended question by indicating which website featured the advertisement, and anyone who provided incorrect responses was excluded $(n=25)$. Twenty-seven participants did not meet the preset qualifications and were removed from the analysis, and five participants were excluded because they admitted they did not read the articles. Thus, 194 participants were included in the analysis.

The procedure was similar to that for Study 1: Respondents read two articles, the first of which contained the information collection manipulation. Then they imagined themselves in a car-buying scenario and viewed an advertisement that related either slightly or closely to the scenario. In addition, the advertisement appeared on either Facebook's or CNN's website (see Appendix 5).

Measures. We measured click-through intentions with a single item, "I would like to click on the advertisement to get further information," using a seven-point Likert scale ("strongly agree" to "strongly disagree"). Then we asked participants to respond to the five-item vulnerability measure from Study $1(\alpha=.93)$.

\section{Results}

Manipulation check. Respondents completed the four items $(\alpha=.90)$ related to how personalized they considered the advertisement and the two questions about Facebook users' awareness of and consent to information collection. The manipulations again worked as intended, according to the comparisons of more versus less personalized advertisements $\left(M_{\text {less }}=4.25\right.$, $\left.M_{\text {more }}=5.83 ; t(192)=-10.07, p<.001\right)$ and overt versus covert conditions (awareness $M_{\text {overt }}=5.26, M_{\text {covert }}=3.43$; $t(192)=-7.59, p<.001 ;$ consent $M_{\text {overt }}=5.99, M_{\text {covert }}=4.54$; 
$t(192)=-6.96, p<.001)$. We also asked respondents to indicate the extent to which they trusted Facebook and CNN, using a semantic differential measure ("untrustworthy-trustworthy"). A paired samples $t$-test revealed that $\mathrm{CNN}$ was significantly more trustworthy than Facebook $\left(M_{\text {Facebook }}=4.08, M_{\mathrm{CNN}}=4.57\right.$; $t(193)=-3.96, p<.001)$.

Click-through intentions. A between-subjects ANOVA with personalization, information collection, context, and their interactions as independent variables and click-through intentions as the dependent variable revealed a significant main effect for personalization $(F(1,186)=31.95, p<.001)$ but no significant main effect for information collection $(F(1,186)=1.01$, $p=.315)$ or context $(F(1,186)=1.69, p=.196)$. The two-way interaction between personalization and information collection was marginally significant $(F(1,186)=3.29, p=.071)$, whereas the two-way interactions between context and personalization $(F(1,186)=.32, p=.572)$ and context and information collection $(F(1,186)=.04, p=.835)$ were both insignificant. The three-way interaction of the independent variables also was not significant $(F(1,186)=1.18, p=.278)$. However, analyzing each context independently, we found that participants displayed lower clickthrough intentions when highly personalized advertisements, collected covertly, appeared on the less trustworthy website compared with the more trustworthy one. ${ }^{4}$ Even though the three-way interaction was not significant, it did not negate the possibility of finding indirect effects through perceived vulnerability (Hayes 2009). Therefore, we explored the mediating role of vulnerability on the relationship between the interaction and click-through intentions.

Mediation. To understand how perceived vulnerability affects click-through intentions in the three-way relationship of personalization, information collection, and context, we conducted a mediation analysis and tested for indirect effects by bootstrapping with 1000 draws using the PROCESS Model 11 (Hayes 2013). We thus confirmed an indirect effect of personalization, through perceived vulnerability, when participants belonged to the covert condition and saw a personalized advertisement on Facebook $(\beta=-.20)$, for which the $95 \%$ confidence interval (CI) excluded zero $(-.45,-.04)$; the same effect did not emerge for CNN $(\beta=-.03)$, and the $95 \% \mathrm{CI}$ included zero $(-.18, .10)$. For participants in the overt condition, perceived vulnerability did not mediate the influence for either Facebook $(\beta=.01 ; 95 \%$ CI

\footnotetext{
4 Among respondents who viewed the advertisement on Facebook, we found a significant interaction between personalization and information collection $(F(1,92)=4.25, p=.042)$, in support of H1. Click-through intentions among participants in the covert condition remained the same, regardless of the level of personalization $\left(M_{\text {less }}=2.48, M_{\text {more }}=3.05 ; F(1,92)=1.13, p=.290\right)$. In contrast, in the overt condition, participants reported greater intentions for a more personalized advertisement $\left(M_{\text {less }}=2.04, M_{\text {more }}=4.12 ; F(1,92)=17.16, p<.001\right)$, as we show in Fig. 6, Panel b. When respondents viewed the advertisement on CNN, the interaction effect of personalization and information collection was not significant $(F(1,94)=.263, p=.609)$. Participants in both the covert $\left(M_{\text {less }}=2.44\right.$, $\left.M_{\text {more }}=3.87 ; F(1,94)=8.55, p=.004\right)$ and overt $\left(M_{\text {less }}=2.46, M_{\text {more }}=4.26\right.$; $F(1,94)=10.64, p=.002)$ conditions noted significantly higher click-through intentions in the more versus less personalized condition. In the more personalized condition, we found no differences across the overt and covert conditions $\left(M_{\text {overt }}=4.26 ; M_{\text {covert }}=3.87 ; F(1,94)=.56, p=.455\right)$.
}

a.Perceived Vulnerability

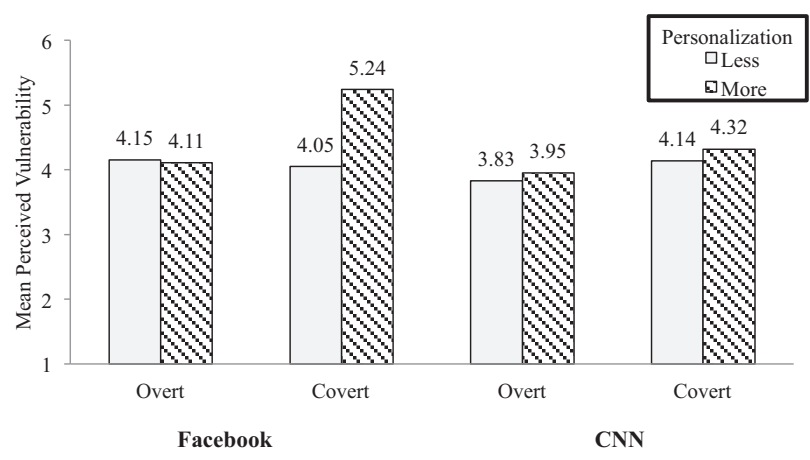

b.Click-Through Intentions

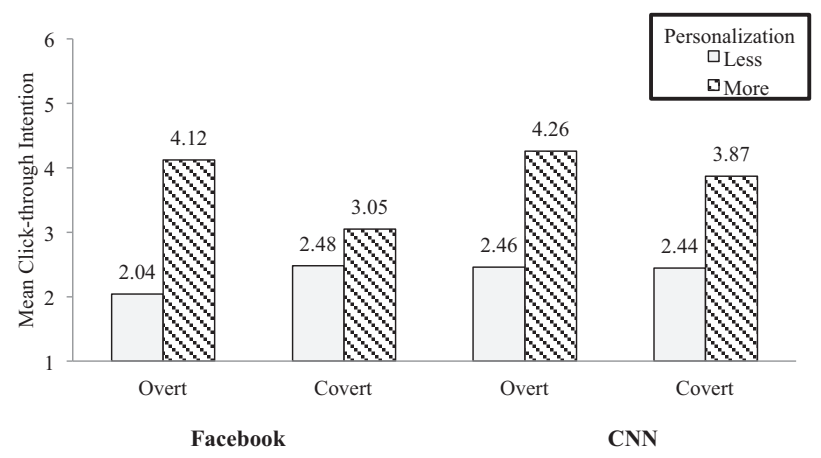

Fig. 6. Study 2: Effects of information collection and personalization in different contexts.

$(-.13, .19))$ or $\mathrm{CNN}(\beta=-.02 ; 95 \% \mathrm{CI}(-.21, .16))$. Therefore, when firms covertly collect data and present highly personalized advertisements, customers feel vulnerable (see Fig. 6, Panel a) and express lower click-through intentions (Fig. 6, Panel b) if the advertisements appear on an untrustworthy website but not if they show up on a trustworthy website, in support of H3.

\section{Discussion}

Study 2 pertains to the differential effects of the medium of an advertisement. We find that the credibility of the website can mitigate the negative effects of covert data collection, in that the results persisted for respondents viewing an advertisement on Facebook, whereas people who viewed the advertisement on $\mathrm{CNN}$ - a more trustworthy website-indicated different clickthrough intentions. If they were exposed to covert information collection, respondents indicated higher click-through intentions for the more personalized advertisement on the trustworthy site, where they did not feel vulnerable. But Facebook attracts approximately 66\% of the U.S. population (Nielson 2013), and retailers prefer to reach this vast market, so other strategies are needed to offset the vulnerability effect.

\section{Study 3}

In response to increasing pressures regarding industry data collection practices, the U.K. Internet Advertising Bureau 
introduced a self-regulatory program that uses icons to inform users about data collection and usage practices associated with each advertisement, as well as an opt-out mechanism (Internet Advertising Bureau UK 2011). Firms appear to consider this icon an effective means to prevent government regulations, yet to the best of our knowledge, no research has tested its effectiveness empirically. Information icons can signal benevolence and integrity beliefs (Schlosser, White, and Lloyd 2006), two key elements of trust, so we posit that they also might offset the negative effects of covert data collections.

\section{Method}

Design and procedure. One hundred forty participants from an online panel who were familiar with Facebook completed the survey. Seventeen respondents did not meet the preset requirements, leaving a sample of 123 participants in the 2 (overt vs. covert information collection) $\times 2$ (icon present vs. absent) between-subjects design. The procedure was similar to that for Study 1: Respondents read two newspaper articles, the first of which contained the information collection manipulation, and then imagined themselves in a car-buying scenario before receiving a highly personalized advertisement. This advertisement contained either no icon or an icon that specified about how their data would be collected, provided an opportunity to learn more about the policies, and offered opt-out choices (Appendix 6).

Measures. We used a seven-point Likert scale ("strongly agree" to "strongly disagree") to measure click-through intentions with a single item: "I would like to click on the advertisement to get further information."

\section{Results}

Manipulation check. The manipulations were successful. Respondents in the overt condition agreed more strongly that Facebook users knew about information collection $\left(M_{\text {overt }}=5.06, M_{\text {covert }}=3.32 ; t(119)=-5.13, p<.001\right.$; two participants did not complete the manipulation checks) and provided consent $\left(M_{\text {overt }}=6.08, M_{\text {covert }}=4.70 ; t(119)=-4.66\right.$, $p<.001$ ), and respondents in the icon condition agreed more with the statement, "The ad directed me to more information about Facebook's data use policies" $\left(M_{\text {icon }}=4.47\right.$, $\left.M_{\text {no icon }}=2.59 ; t(119)=-5.69, p<.001\right)$.

Click-through intentions. A between-subjects ANOVA featured information collection, icons, and their interaction as independent variables and click-through intentions as the dependent variable. There were no significant main effects but a significant interaction effect $(F(1,119)=4.75, p=.031$; see Fig. 7). In line with our previous findings, paired contrasts revealed that respondents exposed to the covert (vs. overt) manipulation had significantly lower click-through intentions when they did not see an information icon $\left(M_{\text {overt }}=4.00, M_{\text {covert }}=2.96 ; F(1,119)=5.48, p=.021\right)$. However, when respondents were presented with an information icon, the differences in click-through intentions between the overt and covert conditions became insignificant $\left(M_{\text {overt }}=3.43\right.$,

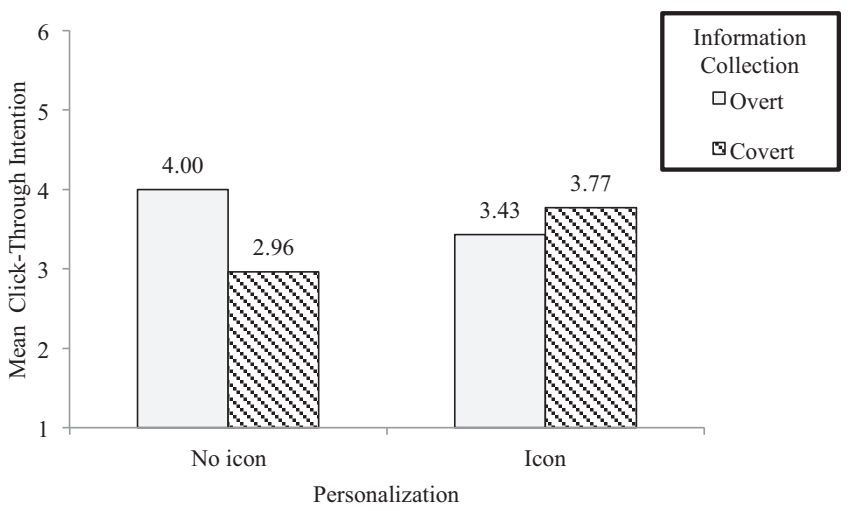

Fig. 7. Study 3: Effects of information collection in the presence or absence of an icon on click-through intentions.

$\left.M_{\text {covert }}=3.77 ; F(1,119)=.58, p=.448\right)$, in support of H4 . Additional contrasts revealed that respondents in the covert condition who received the information icon expressed significantly higher click-through intentions, at a $10 \%$ significance level $\left(M_{\text {icon }}=3.77, M_{\text {no icon }}=2.96 ; F(1,119)=3.08, p=.082\right)$. We found no differences between respondents in the overt condition who received or did not receive the information icon $\left(M_{\text {icon }}=3.43, M_{\text {no icon }}=4.00 ; F(1,119)=1.73, p=.190\right)$.

\section{Discussion}

The findings support the conjecture that when firms covertly collect data from customers and use the information to provide highly personalized advertising, it has negative consequences, such as lower click-through intentions. However, if firms take the initiative to inform customers about their data collection procedures, this negative effect disappears, likely because proactive information provision signals the firms' benevolence and reliability (Kim and Kim 2011), increases trust, and thus minimizes the negative effects of covert data collection. That is, firms can mitigate the negative effects of their covert data collection strategies by providing information and control to users at the moment the personalized advertisement appears.

\section{General Discussion}

With this research, we respond to calls for more empirical generalizations that provide a better understanding of personalization strategies (Grewal et al. 2011). Consistent with prior research (Tam and Ho 2006), we demonstrate that personalization leads to greater click-through intentions-when firms practice overt information collection strategies. When firms practice covert strategies, click-through intentions do not change (Studies 1-2), because respondents who were previously unaware of the information collection felt more vulnerable in the face of a highly personalized advertisement. These findings shed light on the personalization paradox and explain why personalization is not always effective. We also demonstrate that the outcomes vary, depending on the credibility of the website 
on which advertisements appear (Study 2) and the presence of trust-building cues (Study 3).

\section{Implications for Theory}

This study contributes to extant research in three main ways. First, we examine the interaction between information collection and its personalization uses. Prior research offers opposing views of personalization effectiveness (Tam and Ho 2006; White et al. 2008); our field test, secondary data, and main study results help reconcile the debate. When firms openly inform their customers that data collection has taken place, customers find the self-referential and relevant content of the personalized advertisements more useful, so their behavioral intentions improve (Tam and Ho 2006). When consumers are not informed though, customers reject the personalized content and exhibit lower behavioral intentions (White et al. 2008). Even if the firm only informs the customer about its information collection practices as the consumer views the advertisement, the negative reaction disappears. Thus, customer awareness and its accompanying ad hoc consent have central influences on personalization effectiveness.

Second, we show that rejections of personalized services often stem from feelings of vulnerability, which arise when consumers confront a personalized cue. Previous research has relied predominantly on reactance theory to explain this phenomenon (Tucker 2014; White et al. 2008), thus ignoring affective responses (Tucker 2012). By applying the theory of psychological ownership, we clarify the influence of an affective vulnerability experience and test its mediating effect. The results reveal mediation, in support of the robustness of these outcomes. Moreover, in line with research on psychological ownership (Pierce, Kostova, and Dirks 2001), we show that ensuring a consumer's right to information and voice in pertinent decisions significantly reduces feelings of vulnerability. This empirical demonstration of vulnerability and its ramifications for personalization strategies extends research on personalization and psychological ownership. Specifically, our findings reveal a central role of vulnerability — which we operationalize with a new scale-in explaining backlash due to personalization. We also offer an initial empirical investigation of the effects of affective consumer responses on personalized services in social networks.

Third, we test the impact of two trust-building strategies that may offset the experience of vulnerability. Faced with information asymmetry, customers rely on trust heuristics to evaluate personalized advertisements (Kim and Kim 2011), so trustbuilding strategies can counteract the negative effects of covert data collection. If the personalized advertisement appears in a credible context or incorporates information icons that signal trustworthiness, consumers tend to assume they can trust the source.

\section{Implications for Retailers}

The National Retail Federation attributes the growth of online retail sales to retailers' increased ability to use customer information to deliver relevant, targeted marketing. In addition to its theoretical implications, our study offers valuable insights for firms engaging in such online personalization. Retailers, as the most active group using such advertising strategies, should recognize that personalization is not always effective and strategically vary their personalization efforts by carefully selecting which pieces of information to use. For example, firms might rely on information that is generally relevant to a customer but not overly or personally targeted, particularly if they have gathered this latter information from online social network communications. The firms should carefully assess the level of information sensitivity and how closely that information ties to each consumer's identity. Both elements likely determine consumer acceptance of a personalization strategy.

We also recommend transparency about when and how consumer data is being collected. Increased media attention and the spread of personalization practices mean that consumers are increasingly aware that firms collect their information, online and offline. When they receive personalized advertising, these consumers likely express more skepticism toward the retailer, especially if it cites information they did not explicitly consent to provide. Consumers believe that they own such personal information, so if retailers gain access to it, they must inform customers about their data collection strategies and seek implied consent, in the form of consumers' continued usage. Customers must be conscious of this decision, which implies that retailers should be proactive in providing comprehensible, visible notifications of their information collection practices.

Despite the importance of such information policies, it is difficult to implement proactive communications in all circumstances and across the various complex relationships on the Web (e.g., among online publishers, retailers, and data brokers). For targeted advertising in social media, firms thus might benefit from placements on trustworthy websites or from the use of an icon, similar to the one in Study 3, included directly in the advertisements. The icons have been advocated by industry associations as a best practice solution (Internet Advertising Bureau UK 2011) but not universally implemented yet. Such actions help build trust though, which has a direct correlation with recommendation intentions, loyalty, and share of wallet (IBM Institute for Business Value 2012). Our findings indicate the need for wider adoption; such tools can offset negative reactions to personalized advertising, enhance website credibility, and make personalized advertising more acceptable.

\section{Limitations and Avenues for Further Research}

The limitations of this study stem largely from the experimental context we used to test our predictions. First, respondents considered a hypothetical buying scenario. Although the scenario resembled reality, consumer decision making in the real world may differ. Second, it is difficult to say whether the results generalize to other contexts, especially those in which the personalization implies different levels of information sensitivity (Mothersbaugh et al. 2012). Moreover, online publishers other 
than Facebook could produce different results. Further research should address these generalization issues.

Additional research also could delve into customer responses to online and offline personalization strategies. Offline data collection typically occurs when the customer tenders a physical loyalty card; online data collection is less transparent, and the nature of online personalization enables retailers to react to the provided information in real time (Dekimpe et al. 2011), with minimal time between data collection and use. These features could affect how customers react to distinct online and offline personalization strategies, which is an interesting avenue for research. As technological innovations constantly push the acceptable boundaries of information collection, it also would be worthwhile to conduct a longitudinal study to gain insights into any changes in what customers define as acceptable.

More research also could explicate the concept of psychological ownership and its influence over consumer behavior. Shu and Peck (2011) argue that this theory can explain many endowment effects documented in prior literature, yet related research remains limited. It would be helpful to determine which personality traits or demographic characteristics might correlate with psychological ownership. We also call for research into potential variations in ownership perceptions toward personal information that cannot be controlled, such as age, gender, and health, compared with that which can be controlled, such as an address, level of education, or financial information.

Finally, the ever-increasing value of advertising through social media ( $\$ 3.8$ billion in 2011 ; Kharif 2012) suggests the need for more investigations of related issues. Research might consider the role of other network members and their potential influence on the effectiveness of advertising in social media networks. As technology advances, customers can exchange information more easily in real time; a user viewing an advertisement on a social media channel thus may be simultaneously interacting with others. Does this dynamic environment affect advertising success? The size of a network and the strength of the ties within that network also could influence this emerging phenomenon.

\section{Acknowledgements}

The authors appreciate statistical advice from Bram Foubert, helpful comments of Scott Motyka, and data collection support by Maik Idzes, as well as data provided by Adversitement and We Are Blossom.

\section{Appendix A. Information Collection Manipulation}

In the first quarter, Facebook delivered more banner ads to its users than any other Web publisher. They surpassed Microsoft as the market leader, according to the marketing research firm DEK Group.

DEK found that Facebook's share of the display market grew to $20 \%$ in April 2011, up from 10\% in April 2010. In an interview, Guy Bresett, Facebook's vice president for advertising and global operations, said growth in the company's ad business is "steep" and "really healthy"
Mr. Bresett said marketers are coming to Facebook because of the company's ad targeting capabilities. Users are aware that they grant Facebook access to their personal information when they open an account with the social networking site. Facebook informs its users how it analyzes their data to create personalized advertisements. [Facebook steadily follows its users over the social networking site and partner sites, and records their individual activities without their awareness. Facebook conceals from its users how it analyzes their data to create personalized advertisements.]

\section{Appendix B. Scenario}

Imagine that you are a member of the social networking site Facebook. You are an active user, and you communicate to all your friends through this medium.

Please picture that you have to drive to work every day. This morning, your car broke down, and you brought the car to the garage only to find out that it was broken beyond repair. You face a dilemma. You know that you do not have enough money saved up to replace the car, but also that you need a car to get to work.

You remember that one of your friends has recently taken out a car loan. Please picture yourself sending a private message to your friend through Facebook. You tell your friend that you need to take out a loan to finance your new car. You ask if your friend can provide you with more information about it.

\section{Appendix C. Less and More Personalized Advertisements}

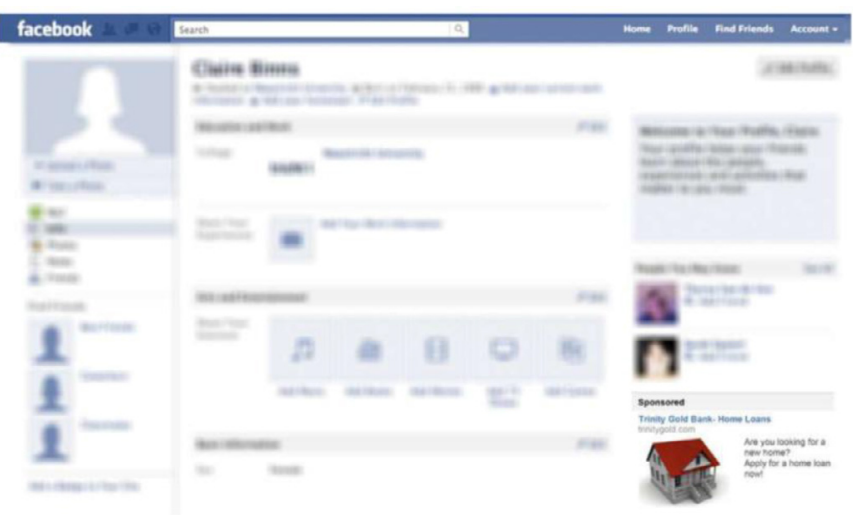

\section{Sponsored}

Trinity Gold Bank- Home Loans trinitygold.com

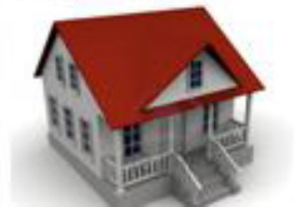

Are you looking for a new home? Apply for a home loan now! 

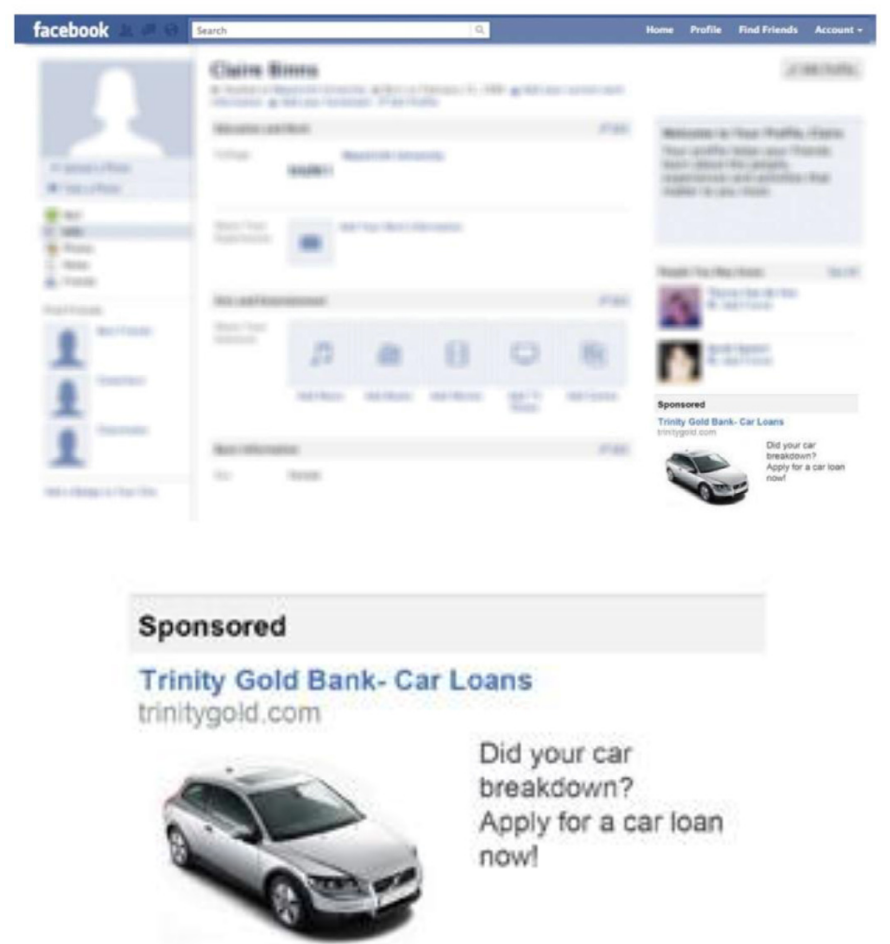

\section{Appendix D. Vulnerability Scale Development Procedure}

From a thorough review of literature, we concluded that instruments available to measure vulnerability did not apply readily to our study. For example, Dinev and Hart (2004) measure individual perceptions of vulnerability as a general understanding of the risks involved when information is revealed during specific contexts, rather than the affective feeling triggered by such instances. Therefore, we followed established procedures and adopted a four-step scale development approach (Netemeyer, Bearden, and Sharma 2003): construct definition and content domain, generating and judging measurement items, designing and conducting studies to develop and refine the scale, and finalizing the scale.

First, in a series of 50 qualitative interviews, we identified that vulnerability went beyond an understanding of risk to include affective feelings of discomfort, as the following quotes represent:

- "An email from my girl friend for example dealing about a bicycle trip was connected to an advertisement about bicycles. This was a bit unpleasant because an email is pretty much an electronic mail which should be private."

- "Well, actually I did observe it that sometimes when you are online and then you suddenly see or receive information and advertisements of which you think: hey I like that! And then I do ask myself how they know this. Because for example this advertisement is about shoes that I saw on a totally different webpage. And actually I think that is rather strange and also a bit frightening. I wonder how far it goes."
- "I just sometimes think its kind of freaky, because you click on a website, and then on Facebook you get ads of websites you have previously visited, and then I'm like; okay, it's kind of freaky that they know I have visited that website and that they now make an ad out of that."

- "someone is breaking into my private sphere ... it is unpleasant."

The interviews revealed an affective feeling associated with information collection, further clarified by the theory of psychological ownership and a subsequent sense of vulnerability. These theoretical insights helped construct the definition of the vulnerability construct.

Second, we integrated the results of the qualitative study and supporting theory to generate a list of 15 scale items that could reliably measure perceived vulnerability. Then 101 students participated in an open-ended elicitation task (Hardesty, Bearden, and Carlson 2007). As part of the task, each participant listed all words associated with vulnerability. Three judges coded the items by evaluating the degree to which each item was representative of the definition of vulnerability. If less than two-thirds of the judges did not affirm an item, we removed it. This process led to the retention of seven items.

Third, we conducted a pilot test with 108 students; for item reduction efforts, college students are an acceptable population (Netemeyer, Bearden, and Sharma 2003). In LISREL 8 , we ran an exploratory factory analysis, and the modification index values indicated a single-factor model with five items (Lastovicka et al. 1999). The model revealed a small chi-square value $\left(\chi^{2}=2.13 ; \mathrm{df}=5 ; p=.831\right)$, and a good fit (root mean square error of approximation $<.01$, goodness-offit index $=.99$, adjusted goodness-of-fit index $=.98$, normed fit index $=.99)$. The corrected item-to-total correlations were all above .50 (Brocato, Voorhees, and Baker, 2012), as well the interitem correlations (Netemeyer, Bearden, and Sharma 2003). The Cronbach's alpha was .864 .

Fourth, our main studies demonstrate the discriminant, convergent, and nomological validity of the measure. Specifically, we conducted a study that contained a cognitive response measure (privacy) together with perceived vulnerability $(n=39)$. The average variance extracted (AVE) of the perceived vulnerability construct was greater than .50 (Bagozzi and Yi 1988; AVE =.764), and the composite reliability (CR) exceeded the recommended minimum of .7 (Fornell and Larcker 1981; CR =.941). In support of discriminant validity, the AVE of perceived vulnerability was greater than the shared variance between perceived vulnerability and privacy $\left(\mathrm{AVE}=.764>r^{2}=.230\right)$. Perceived vulnerability and privacy are not only moderately correlated $(r=-.480 ; p=.002)$ but also move in similar directions, as predicted by theory (lower values indicate higher privacy concerns). This relationship, as well as those between perceived vulnerability and the constructs in Studies 1 and 2, provide support for our measure of perceived vulnerability. 


\section{Appendix E. CNN Screengrab}

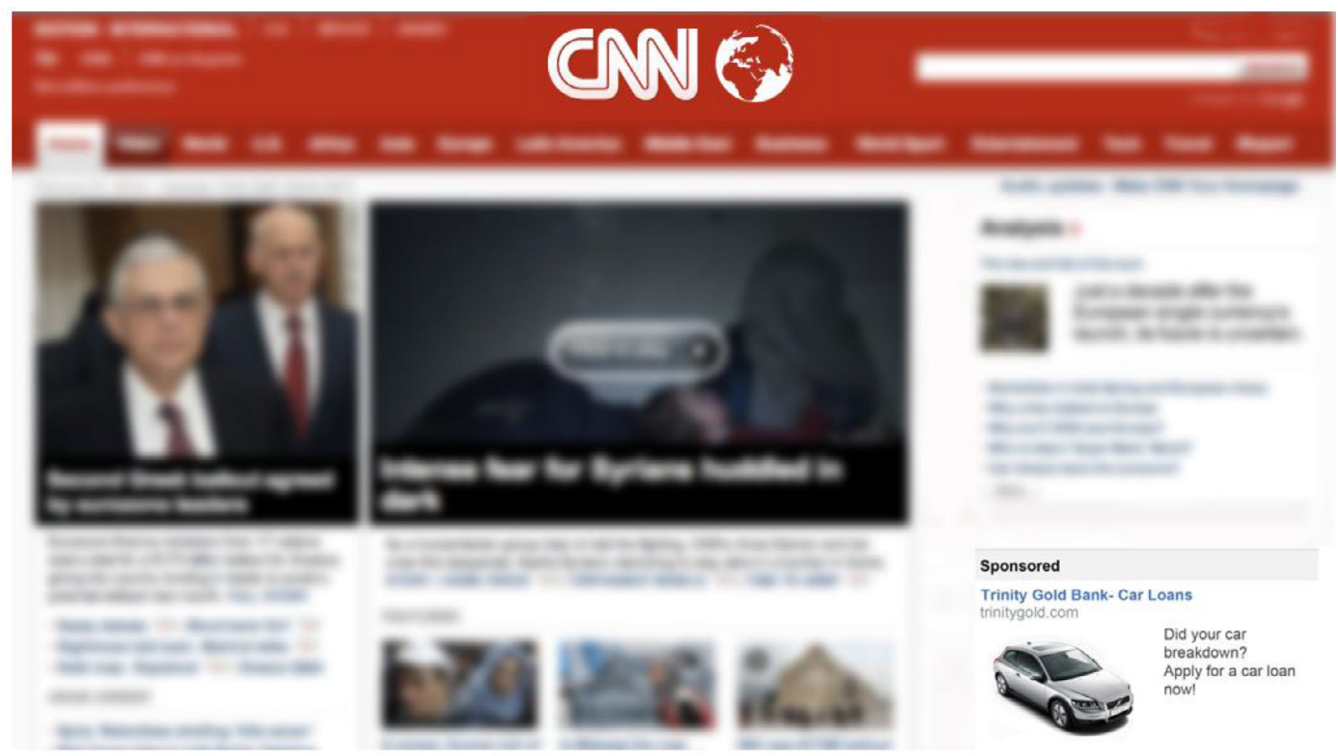

\section{Appendix F. Facebook Screengrab}

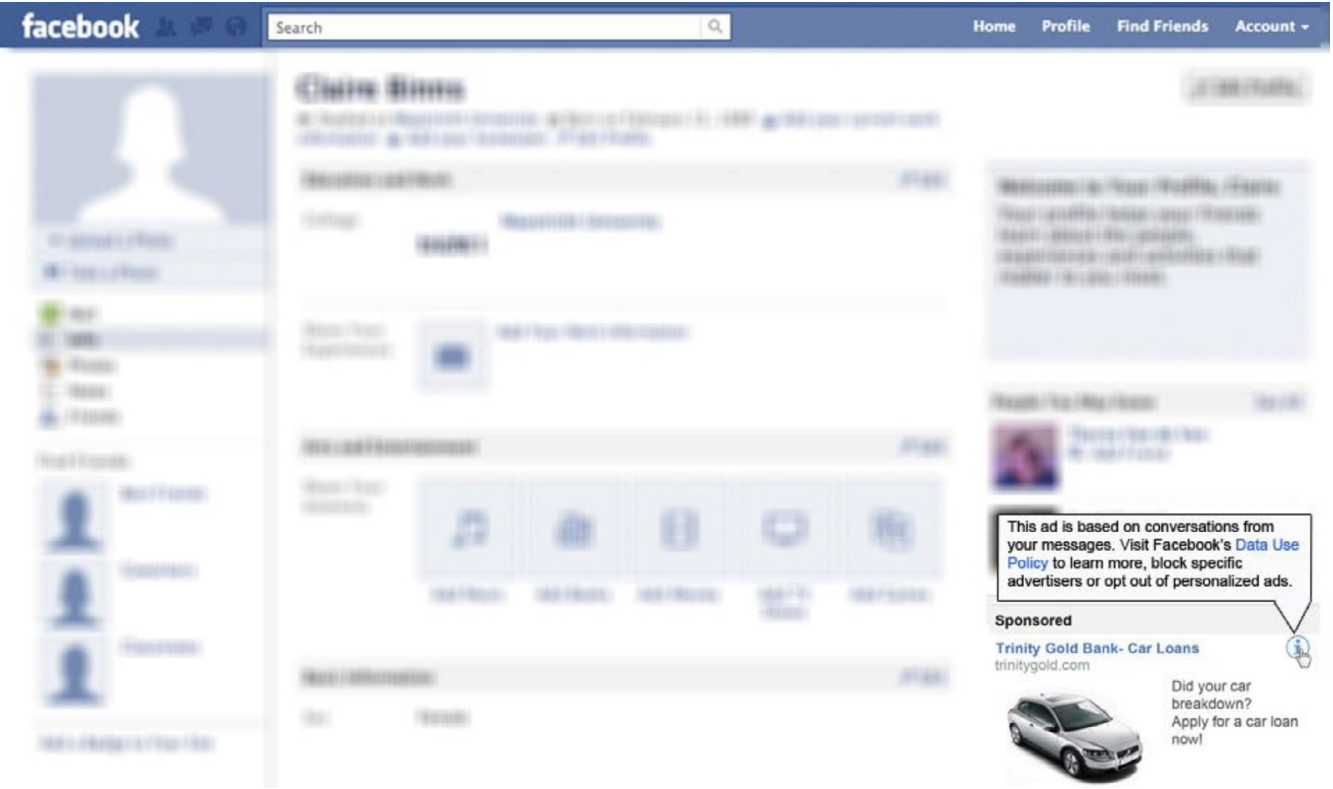

\section{References}

Aaker, David A. and Phillip K. Brown (1972), "Evaluating Vehicle Source Effects," Journal of Advertising Research, 12 (4), 11-6.

Andreasen, Alan R., Elizabeth Cooper-Martin and N. Craig Smith (1994), Who Is the Vulnerable Consumer? The Implications for Marketing and Public Policy of Objective and Subjective Consumer Vulnerability,. Working paper Angwin, Julia (2012), "Online Tracking Ramps Up," The Wall Street Journal, June 17 (accessed September 25, 2012) [available at http://online.wsj. com/article/SB10001424052702303836404577472491637833420.html].
Ansari, Asim and Carl F. Mela (2003), "E-Customization," Journal of Marketing Research, 40 (2), 131-45.

Arnold, Mark J. and Kristy E. Reynolds (2009), "Affect and Retail Shopping Behavior: Understanding the Role of Mood Regulation and Regulatory Focus," Journal of Retailing, 85 (3), 308-20.

Arora, Neeraj, Xavier Dreze, Anindya Ghose, James D. Hess, Raghuram Iyengar, Bing Jing, Yogesh Joshi, V. Kumar, Nicholas Lurie, Scott Neslin, S. Sajeesh, Meng Su, Niladri Syam, Jacquelyn Thomas and Z. John Zhang (2008), "Putting One-to-One Marketing to Work: Personalization, Customization, and Choice," Marketing Letters, 19, 305-21. 
Avey, James B., Bruce J. Avolio, Craig D. Crossley and Fred Luthans (2009), "Psychological Ownership: Theoretical Extensions, Measurement, and Relation to Work Outcomes," Journal of Organizational Behavior, 30, 173-91.

Avnet, Tamar, Michel Tuan Pham and Andrew T. Stephen (2012), "Consumers' Trust in Feelings as Information," Journal of Consumer Research, 39 (4), 720-35.

Awad, Naveen Farag and M.S. Krishnan (2006), “The Personalization Privacy Paradox: An Empirical Evaluation of Information Transparency and the Willingness to be Profiled Online for Personalization," MIS Quarterly, 30 (1), 13-28.

Bagozzi, Richard P. and Youjae Yi (1988), "On the Evaluation of Structural Equation Models," Journal of the Academy of Marketing Science, 16 (1), 74-94.

Baker, Stacey Menzel, James W. Gentry and Terri L. Rittenburg (2005), "Building Understanding of the Domain of Consumer Vulnerability," Journal of Macromarketing, 25 (2), 128-39.

Bandyopadhyay, Soumava (2009), "Antecedents and Consequences of Consumers' Online Privacy Concerns," Journal of Business and Economics Research, 7 (3), 41-8.

Bart, Yakov, Venkatesh Shankar, Fareena Sultan and Glen L. Urban (2005), "Are the Drivers and Role of Online Trust the Same for All Websites and Consumers? A Large Scale Exploratory Study," Journal of Marketing, 69 (4), 133-52.

Belk, Russell W. (1988), "Possessions and the Extended Self," Journal of Consumer Research, 15 (2), 139-68.

Brehm, Jack W. (1966), A Theory of Psychological Reactance, New York: Academic Press.

Brocato, E. Deanne, Clay M. Voorhees and Julie Baker (2012), "Understanding the Influence of Cues from Other Customers in the Service Experience: A Scale Development and Validation," Journal of Retailing, 88 (3), 384-98.

Chellappa, Ramnath K. and Shivendu Shivendu (2010), "Mechanism Design for 'Free' but 'No Free Disposal' Services: The Economics of Personalization under Privacy Concerns," Management Science, 56 (10), 1766-80.

Choi, Sejung Marina and Nora J. Rifon (2002), "Antecedents and Consequences of Web Advertising Credibility: A Study of Consumer Response to Banner Ads," Journal of Interactive Advertising, 3 (1), 12-24.

comScore (2011), "U.S. Online Display Advertising Market Delivers 1.1 Trillion Impressions in Q1 2011," May 4 (accessed September 24, 2012) [available at http://www.comscore.com/Press_Events/Press_Releases/2011/5/U.S._ Online_Display_Advertising_Market_Delivers_1.1_Trillion_Impressions_in_ Q1_2011].

Dekimpe, Marnik G., Katrijn Gielens, Jagmohan Raju and Jacquelyn S. Thomas (2011), "Strategic Assortment Decisions in Information-Intensive and Turbulent Environments," Journal of Retailing, 87 (S1), S17-28.

Dijkstra, Arie (2005), "Working Mechanisms of Computer-Tailored Health Education: Evidence from Smoking Cessation," Health Education Research, 20 (5), 527-39.

Dinev, Tamara and Paul Hart (2004), "Internet Privacy Concerns and Their Antecedents: Measurement Validity and a Regression Model," Behavior and Information Technology, 23 (6), 413-22

DutchNews.nl (2013), "Dutch Cookie Law to be Watered Down," May 20 (accessed August 13, 2013) [available at http://www.dutchnews.nl/news/ archives/2013/05/dutch_cookie_law_to_be_watered.php].

Fitzsimons, Gavan J. and Donald R. Lehmann (2004), "Reactance to Recommendations: When Unsolicited Advice Yields Contrary Responses," Marketing Science, 23 (1), 82-94

Fornell, Claes and David Larcker (1981), "Evaluating Structural Equation Models with Unobservable Variables and Measurement Error," Journal of Marketing Research, 18 (1), 39-50.

Goldfarb, Avi and Catherine Tucker (2011), "Online Display Advertising: Targeting and Obtrusiveness," Marketing Science, 30 (3), 389-404.

Grewal, Dhruv, Kusum L. Ailawadi, Dinesh Gauri, Kevin Hall, Praveen Kopalle and Jane R. Robertson (2011), "Innovations in Retail Pricing and Promotions," Journal of Retailing, 87 (S1), S43-52.

Gupta, Pranjal, Manjit S. Yadav and Rajan Varadarajan (2009), "How TaskFacilitative Interactive Tools Foster Buyers' Trust in Online Retailers: A
Process View of Trust Development in the Electronic Marketplace," Journal of Retailing, 85 (2), 159-76.

Hardesty, David M., William O. Bearden and Jay P. Carlson (2007), "Persuasion Knowledge and Consumer Reactions to Pricing Tactics," Journal of Retailing, 83 (2), 199-210.

Hawkings, Gary (2012), "Will Big Data Kill All But the Biggest Retailers?” Harvard Business Review, September 18 (accessed September 25, 2012) [available at http://blogs.hbr.org/cs/2012/09/will_big_data_kill_all_but_the.html].

Hayes, Andrew F. (2009), "Beyond Baron and Kenny: Statistical Mediation Analysis in the New Millennium," Communication Monographs, 76 (4), 408-20.

(2013), PROCESS: A Versatile Computational Tool for Observed Variable Mediation, Moderation, and Conditional Process Modeling, White paper. http://www.afhayes.com/public/process2012.pdf

IBM Institute for Business Value (2012), "Winning Over the Empowered Consumer: Why Trust Matters.” (accessed September 5, 2013) [available at http://www.nrf.com/modules.php?name=News\&op=viewlive\&sp_id=1343 \&parent_id=960\&peer_rev=1\&nrf_or=0].

Interactive Advertising Bureau (2012), "Internet Ad Revenues Hit \$31 Billion in 2011, Historic High Up 22\% Over 2010 Record Breaking Numbers," April 18 (available September 21, 2012) [available at http://www.iab.net/ about_the_iab/recent_press_releases/press_release_archive/press_release/pr041812]

Interactive Advertising Bureaux Europe (2011), "IAB Europe Urges EU Member States to Consider Negative Impact of an Overly Strict Consent for Cookies (and Other Storing Technologies),” June 10 (accessed July 6, 2012) [available at http://www.iabeurope.eu/public-affairs/e-privacy-directive/ cookiedemosite-061011.aspx].

Internet Advertising Bureau UK (2011), "Europe Commits to Self-Regulation," April 14 (accessed June 14, 2012) [available at http://www.iabuk.net/news/ europe-commits-to-self-regulation].

James, William (1981), The Principles of Psychology: Volume I, Cambridge, MA: Harvard University Press.

John, Leslie K., Alessandro Acquisti and George Loewenstein (2011), "Strangers on a Plane: Context-Dependent Willingness to Divulge Sensitive Information," Journal of Consumer Research, 37 (February), $858-73$.

Kharif, Olga (2012), "Social-Media Ad Spending to Jump to $\$ 9.8$ Billion in 2016," Bloomberg, May 15 (accessed October 10, 2012) [available at http://www.bloomberg.com/news/2012-05-15/social-media-ad-spending-tojump-to-9-8-billion-in-2016.html].

Kim, Kyongseok and Jooyoung Kim (2011), "Third-Party Privacy Certification as an Online Advertising Strategy: An Investigation of the Factors Affecting the Relationship between Third-Party Certification and Initial Trust," Journal of Interactive Marketing, 25, 145-58.

Lastovicka, John L., Lance A. Bettencourt, Renée Shaw Hughner and Ronald J. Kuntze (1999), "Lifestyle of the Tight and Frugal: Theory and Measurement," Journal of Consumer Research, 26 (1), 85-98.

Lwin, May O., Andrea J.S. Stanaland and Anthony D. Miyazaki (2008), "Protecting Children's Privacy Online: How Parental Mediation Strategies Affect Website Safeguard Effectiveness," Journal of Retailing, 84 (2), 205-17.

McCann Worldwide (2011), "The Truth About Privacy," (accessed July 10, 2012) [available at http://truthcentral.mccann.com/truth-studies/\#the-truthabout-privacy].

Milne, George R., Shalini Bahl and Andrew Rohm (2008), "Toward a Framework for Assessing Covert Marketing Practices," Journal of Public Policy \& Marketing, 27 (1), 57-62

Miyazaki, Anthony D. (2008), "Online Privacy and the Disclosure of Cookie Use: Effects on Consumer Trust and Anticipated Patronage," Journal of Public Policy \& Marketing, 27 (1), 19-33.

Montgomery, Alan L. and Michael D. Smith (2009), "Prospects for Personalization on the Internet," Journal of Interactive Marketing, 23, 130-7.

Mothersbaugh, David L., William K. Foxx II, Sharon E. Beatty and Sijun Wang (2012), "Disclosure Antecedents in an Online Service Context: The Role of Sensitivity of Information," Journal of Service Research, 15 (1), 76-98.

Muller, Dominique, Charles M. Judd and Vincent Y. Yzerbyt (2005), "When Moderation Is Mediated and Mediation Is Moderated," Journal of Personality and Social Psychology, 89 (6), 852-63. 
Murthi, B.P.S. and Sumit Sarkar (2003), "The Role of the Management Sciences in Research on Personalization," Management Science, 49 (10), 1344-62.

National Retail Federation (n.d.), "Comments of The National Retail Federation and Shop.org Before the Federal Trade Commission on Preliminary FTC Staff Report: 'Protecting Consumer Privacy in an Era of Rapid Change' A Proposed Framework for Businesses And Policymakers." (accessed September 4, 2013) [available at http://ftc.gov/os/comments/ privacyreportframework/00419-58061.pdf].

Netemeyer, Richard G., William O. Bearden and Subhash Sharma (2003), Scaling Procedures: Issues and Applications, Thousand Oaks, CA: Sage Publications.

Nielson (2013), “Top 10 List for Global Web Parent Companies,” May (accessed August 13, 2013) [available at http://www.nielsen.com/us/en/top10s.html].

Pan, Yue and George M. Zinkhan (2006), "Exploring the Impact of Online Privacy Disclosures on Consumer Trust," Journal of Retailing, 82 (4), 331-8.

Pavlou, Paul A. (2011), "State of the Information Privacy Literature: Where We Are Now and Where We Should Go?," MIS Quarterly, 35 (4), 977-88.

Pavlou, Paul A., Huigang Liang and Yajiong Xue (2007), "Understanding and Mitigating Uncertainty in Online Exchange Relationships: A PrincipalAgent Perspective," MIS Quarterly, 31 (1), 105-36.

Pierce, Jon L., Tatiana Kostova and Kurt T. Dirks (2001), "Toward a Theory of Psychological Ownership in Organizations," Academy of Management Review, 26 (2), 298-310.

Preacher, Kristopher J., Derek D. Rucker and Andrew F. Hayes (2007), "Addressing Moderated Mediation Hypotheses: Theory, Methods, and Prescriptions," Multivariate Behavioral Research, 42 (1), 185-227.

Rossi, Peter E., Robert E. McCulloch and Greg M. Allenby (1996), "The Value of Purchase History Data in Target Marketing," Marketing Science, 15 (4), $321-40$.

Rousseau, Denise M., Sim B. Sitkin, Ronald S. Burt and Colin Camerer (1998), "Not So Different After All: Cross Discipline View of Trust," Academy of Management Review, 23 (3), 393-404.

Rust, Roland T. and Tuck Siong Chung (2006), "Marketing Models of Service and Relationships," Marketing Science, 25 (6), 560-80.

Schlosser, Ann E., Tiffany Barnett White and Susan M. Lloyd (2006), "Converting Web Site Visitors into Buyers: How Web Site Investment Increases Consumer Trusting Beliefs and Online Purchase Intentions," Journal of Marketing, 70 (2), 133-48.

Shamdasani, Prem N., Andrea J.S. Stanaland and Juliana Tan (2001), "Location, Location, Location: Insights for Advertising Placement on the Web," Journal of Advertising Research, 41 (4), 7-21.

Shankar, Venkatesh, J. Jeffrey Inman, Murali Mantrala, Eileen Kelley and Ross Rizley (2011), "Innovations in Shopper Marketing: Current Insight and Future Research Issues," Journal of Retailing, 87 (S1), S29-42.

Shen, Anyuan and A. Dwayne Ball (2009), "Is Personalization of Services Always a Good Thing? Exploring the Role of Technology-Mediated Personalization (TMP) in Service Relationships," Journal of Services Marketing, 23 (2), 79-91.

Shiv, Baba and Alexander Fedorikhin (1999), "Heart and Mind in Conflict: The Interplay of Affect and Cognition in Consumer Decision Making," Journal of Consumer Research, 26 (3), 278-92.
Shu, Suzanne B. and Joann Peck (2011), "Psychological Ownership and Affective Reaction: Emotional Attachment Process Variables and the Endowment Effect," Journal of Consumer Psychology, 21 (4), 439-52.

Singer, Natasha (2010), "Shoppers Who Can't Have Secrets," The New York Times, May 1 (accessed September 25, 2012) [available at http://www. nytimes.com/2010/05/02/business/02stream.html].

Singer, Natasha (2012), "E-Tailer Customization: Convenient or Creepy?" The New York Times, June 23 (accessed July 18, 2012) [available at http://www.nytimes.com/2012/06/24/technology/e-tailer-customizationwhats-convenient-and-whats-just-plain-creepy.html?ref=natashasinger].

Song, Ji Hee and George M. Zinkhan (2008), "Determinants of Perceived Web Site Interactivity," Journal of Marketing, 72 (March), 99-113.

Stewart, Katherine J. (2003), "Trust Transfer in the World Wide Web," Organization Science, 14 (1), 5-17.

Sundar, S. Shyam and Sampada S. Marathe (2010), "Personalization versus Customization: The Importance of Agency, Privacy, and Power Usage," Human Communication Research, 36, 298-322.

Tam, Kar Yan and Shuk Ying Ho (2006), "Understanding the Impact of Web Personalization on User Information Processing and Decision Outcomes," MIS Quarterly, 30 (4), 865-90.

Tolchinski, Paul D., Michael K. McCuddy, Jerome Adams, Daniel C. Ganster, Richard W. Woodman and Howard L. Fromkin (1981), "Employee Perceptions of Invasion of Privacy: A Field Simulation Experiment," Journal of Applied Psychology, 66 (3), 308-13.

Tucker, Catherine (2012), "The Economics of Advertising and Privacy," International Journal of Industrial Organization, 30 (3), 326-9.

(2014), "Social Networks, Personalized Advertising, and Privacy Controls," Journal of Marketing Research, 51 (5), 546-62.

Turow, Joseph, Jennifer King, Chris Jay Hoofnagle, Amy Bleakley, and Michael Hennessy (2009), "Americans Reject Tailored Advertising and Three Activities that Enable It," Working Paper (accessed April 17, 2012) [available at http://ssrn.com/abstract=1478214].

Urban, Glen L., Cinda Amyx and Antonio Lorenzon (2009), "Online Trust: State of The Art, New Frontiers, and Research Potential," Journal of Interactive Marketing, 23 (2), 179-90.

Verhoef, Peter C., Rajkumar Venkatesan, Leigh McAlister, Edward C. Malthouse, Manfred Krafft and Shankar Ganesan (2010), "CRM in Data-Rich Multichannel Retailing Environments: A Review and Future Research Directions," Journal of Interactive Marketing, 24, 121-37.

Vesanen, Jari (2007), "What is Personalization? A Conceptual Framework," European Journal of Marketing, 41 (5), 409-18

Wang, Sijun, Sharon E. Beatty and William Foxx (2004), "Signaling the Trustworthiness of Small Online Retailers," Journal of Interactive Marketing, 18 (1), 53-69.

White, Tiffany Barnett, Debra L. Zahay, Helge Thorbjфrnsen and Sharon Shavitt (2008), "Getting Too Personal: Reactance to Highly Personalized Email Solicitations," Marketing Letters, 19, 39-50.

Wolfinbarger, Mary and Mary C. Gilly (2003), "eTailQ: Dimensionalizing, Measuring, and Predicting eTail Quality," Journal of Retailing, 79, $183-98$.

Zhang, Jie and Michel Wedel (2009), "The Effectiveness of Customized Promotions in Online and Offline Stores," Journal of Marketing Research, 46 (2), 190-206. 